\title{
Comparative study of prophylactic ilioinguinal neurectomy and preservation of ilioinguinal nerve in open mesh repair of inguinal hernia
}

\author{
Sangolagi P. ${ }^{1}$, Tukaram A.K. ${ }^{2}$ \\ ${ }^{1}$ Dr. Pramoda Sangolagi, Senior Resident, ${ }^{2}$ Dr. Arun Kumar Tukaram, Assistant Professor; both authors are affiliated \\ with Department of General Surgery, ESICMC, Kalaburagi, Karnataka, India.
}

Corresponding Author: Dr. Arun Kumar Tukaram, Assistant Professor, Department of General Surgery, ESICMC, Kalaburagi. E-mail: drarunuttam@yahoo.com

\begin{abstract}
Background: Inguinal hernia is one of the most common surgery done in any hospital. Complaints of Chronic inguinal pain is one of the common problem these patients. This study aims at evaluating the long-term outcomes of neuralgia and paraesthesia following routine ilioinguinal nerve division, compared to nerve preservation when performing Lichtenstein's tension free inguinal hernia repair. Methods: The present study is a randomized controlled trial of 80 cases of inguinal hernias admitted in General Surgery Department in ESIC Medical College, Kalaburagi from January 2017 to June 2018. The patients were randomly chosen into Lichtenstein hernia repair with ilioinguinal neurectomy or Lichtenstein hernia repair with nerve preservation. After surgery, all patients were monitored carefully for pain and paraesthesia. Pain was assessed using visual analogue scale. Paraesthesia was assessed by the monofilament test and evaluated after comparison with the opposite side. Results: In the present study, the incidence of pain as well as the severity of pain is far higher in the nerve preservation study group as opposed to the neurectomy study group. Hypoesthesia is not a significant complication following ilioinguinal neurectomy and does not significantly add to the morbidity of the patient. Conclusions: Prophylactic neurectomy can be an appropriate solution in the prevention of chronic groin pain following Lichtenstein inguinal hernia repair and can be considered as an ideal inclusion into the standard hernia repair procedures. Hypoesthesia is not a significant complication following ilioinguinal neurectomy and does not significantly add to the morbidity of the patient.
\end{abstract}

Keywords: Inguinal hernia, Ilioinguinal nerve, Neurectomy

\section{Introduction}

A hernia is a protrusion of a viscus or part of a viscus through an abnormal opening in the walls of its containing cavity. The external abdominal hernia is the most common form, the most frequent varieties being the inguinal, femoral and umbilical, accounting for $75 \%$ of cases. Recently, with more attention to patient outcomes, chronic groin pain has replaced recurrence as the primary complication after open inguinal hernia repair. Several large series with systematic follow-up have reported pain rates ranging from $29 \%$ to $76 \%$. Chronic pain following surgery has emerged as a common and sometimes severe problem that can significantly affect a patient's, health-related, quality of life $[1,2]$.

Manuscript Received: $30^{\text {th }}$ November 2018

Reviewed: $8^{\text {th }}$ December 2018

Author Corrected: $14^{\text {th }}$ December 2018

Accepted for Publication: $18^{\text {th }}$ December 2018
Chronic post herniorrhaphy groin pain is defined as pain lasting for more than 3 months after surgery. It is one of the most important complications occurring after inguinal hernia repair and it occurs with greater frequency than previously thought. A review of studies published between 1987 to 2000 showed an overall incidence of $25 \%$ with $10 \%$ of patients having pain fitting a definition of moderate or severe [3].

Treatment is often difficult and challenging. Inguinal hernia is one of the most common surgery done in any hospital. Complaints of Chronic inguinal pain is one of the common problems these patients.

The concept of routine neurectomy in surgery is not unique to inguinal hernia repairs. Routine neurectomy is often performed during axillary and neck dissections in 


\section{Original Research Article}

which the Intercosto brachial and greater auricular nerves are sacrificed. Routine ilioinguinal nerve excision has been proposed as a means to avoid the troubling complication of long term post herniorrhaphy neuralgia [4].

The present study was done with the aim to compare and correlate the therapeutic effectiveness of routine ilioinguinal neurectomy versus nerve preservation in
Lichtenstein inguinal hernia repair with respect to chronic post-operative groin pain and post-operative paraesthesia.

Need for the Study- aim to compare the therapeutic effectiveness of routine ilioinguinal neurectomy versus nerve preservation in Lichtenstein inguinal hernia repair with respect to chronic post-operative groin pain and post-operative paraesthesia

\section{Materials and Methods}

Place of Study: ESIC Medical College, Kalaburagi

Type of Study: A Randomized controlled trial Study

Period of Study: January 2017 to June 2018

Period required for Data collection: 2 years

Period required for Data analysis and reporting: 6 months

80 cases for the purpose of the study were selected on the basis of the random sampling method and after taking valid informed consent. 40 cases included in each group. Neurectomy case group named as Group A and Preservation of nerve group named as group B

\section{Inclusion criteria}

- all patients above 18 years of age;

- both direct and indirect inguinal hernias who undergo Lichtenstein Mesh Repair were included in the study

\section{Exclusion criteria}

- Recurrent hernias

- Hernia with complications like obstructed/strangulated hernia was excluded in the study.

The data was collected in a prepared proforma. The diagnosis of inguinal hernia was made by clinical examination. Preoperative evaluation included history and clinical findings. Routine lab investigations like $\mathrm{Hb} \%$, urine examination, RBS, serum urea and creatinine, HIV, HBsAg were done. Ultra sonographic evaluation of the abdomen was done in symptomatic patients above age 40 years to look for prostatomegaly. X-ray and ECG were done for all patients for anesthetic evaluation.

Preoperatively, improvement of the nutritional status of the patient, when required was done. Any respiratory infection if present was treated.

Abstinence from smoking/alcohol was advised. Patient was advised on appropriate breathing exercises. The type of anesthesia used was spinal anesthesia for all the cases. The patients were randomly chosen into Lichtenstein hernia repair with ilioinguinal neurectomy (Group A) or Lichtenstein hernia repair with nerve preservation (Group B).

All the Ilio inguinal nerve excised from the neurectomy group (Group A) were sent to histopathology lab for confirmation. A single dose of preoperative broad spectrum antibiotic was given followed by the same for total of 3 doses postoperatively. Analgesics was given postoperatively for 2 days and SOS later. After surgery, all patients were monitored carefully for pain and paraesthesia. Pain was assessed using Visual analogue scale. Paraesthesia was assessed by the monofilament test and evaluated after comparison with the opposite side. The patients were discharged when fit and were asked to come for regular follow up at 1 month, 3 months, and 6 months. There were 4 dropouts at end of 6 months. The patients were advised to return to pre-hernia lifestyle except lifting of heavy weights. Patients were evaluatedfor pain at rest, during normal activities and during vigorous activities at every follow up. The age/sex incidence, mode of presentation, surgical treatment, postoperative pain and paraesthesia were all evaluated. 


\section{UNIVERSAL PAIN ASSESSMENT TOOL}

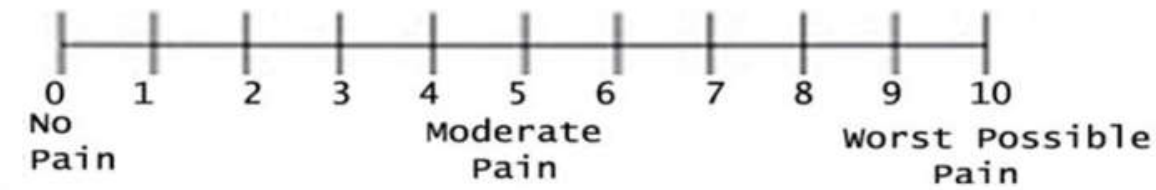

\section{Wong-Baker FACES Pain Rating Scale}

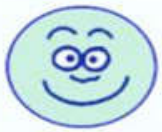

No Hurt

0

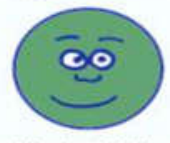

Hurts Little Bit

1-2

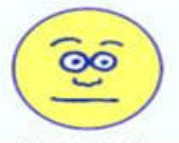

Hurts Little More 3-4

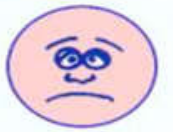

Hurts Even More

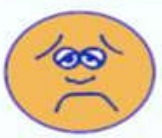

Hurts Whole Lot

7-8

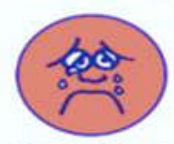

Hurts Worst

$9-10$

Figure-1: Visual analogue scale.

\section{Results}

A total of 80 patients were taken for the study. These patients were randomized with 40 patients each in neurectomy and nerve preservation group. Ten patients did not come for follow up regularly after discharge and therefore, only onemonth data were available for them. These patients were not considered in the results of the study. Rest of the patients was followed for a period of 6 months. In the present study, the minimum age of the patient presenting with inguinal hernia was 18 years in the neurectomy group and 20 years in the nerve preservation group, while the oldest being 68 years in the neurectomy group and 70 years in the nerve preservation group (Table 1).

Table-1: Age distribution.

\begin{tabular}{|c|c|c|}
\hline Age & Neurectomy (Group A) & Preservation OF Nerve(Group B) \\
\hline$<20$ & 4 & 3 \\
\hline $21-30$ & 6 & 7 \\
\hline $31-40$ & 14 & 7 \\
\hline $41-50$ & 8 & 7 \\
\hline $51-60$ & 5 & 3 \\
\hline $61-70$ & 3 & $\mathbf{4 0}$ \\
\hline
\end{tabular}

In the present study, only one female patient was present in the nerve preservation group.

Table- 2: Diagnosis; type of Inguinal Hernia.

\begin{tabular}{|c|c|c|}
\hline \multirow{2}{*}{ Inguinal Hernia } & \multicolumn{2}{|c|}{ Surgery n (\%) } \\
\cline { 2 - 3 } & Neurectomy (Group A) & Preservation of nerve ( Group B) \\
\hline Right direct & $9(22.5)$ & $5(12.5)$ \\
\hline Left direct & $8(20)$ & $6(15)$ \\
\hline Right indirect & $16(40)$ & $22(55)$ \\
\hline Left indirect & $7(17.5)$ & $7(17.5)$ \\
\hline Total & $\mathbf{4 0}(\mathbf{1 0 0})$ & $\mathbf{4 0}(\mathbf{1 0 0})$ \\
\hline
\end{tabular}

In the present study, the incidence of right indirect hernia was the highest, being $40 \%$ in neurectomy group and $55 \%$ in nerve preservation group. The least was of right direct hernia. 
Original Research Article

Table-3: Pain at rest.

\begin{tabular}{|c|c|c|c|c|}
\hline \multirow{2}{*}{ Pain at rest } & \multicolumn{4}{|c|}{ Follow up n (\%) } \\
\cline { 2 - 5 } & & $\mathbf{1}$ month & $\mathbf{3}$ months & 6 months \\
\hline \multirow{2}{*}{\begin{tabular}{c} 
Neurectomy \\
\cline { 2 - 5 }
\end{tabular}} & Absent & $34(85)$ & $33(97)$ & $34(100)$ \\
\cline { 2 - 5 } & Present & $6(15)$ & $1(3)$ & 0 \\
\cline { 2 - 5 } & Total & $\mathbf{4 0 ( 1 0 0 )}$ & $\mathbf{3 4 ( 1 0 0 )}$ & $33(100)$ \\
\cline { 2 - 5 } Preservation of & Absent & $34(85)$ & $33(91)$ & $3(9)$ \\
\cline { 2 - 5 } & Present & $6(15)$ & $3(9)$ & $\mathbf{3 6}(\mathbf{1 0 0})$ \\
\cline { 2 - 5 }
\end{tabular}

Pain at rest was present in $9 \%$ of the patients in nerve preservation group after 6 months $(p=0.143)$ statistically insignificant.

Table-4: Pain after normal daily activities.

\begin{tabular}{|c|c|c|c|c|}
\hline \multirow{2}{*}{$\begin{array}{c}\text { Pain after normal } \\
\text { daily activities }\end{array}$} & \multicolumn{4}{|c|}{ Follow Up n (\%) } \\
\cline { 2 - 5 } & & $\mathbf{1}$ month & $\mathbf{3}$ months & 6 months \\
\hline \multirow{2}{*}{\begin{tabular}{c} 
Neurectomy \\
\cline { 2 - 5 }
\end{tabular}} & Absent & $18(45)$ & $27(79)$ & $30(88.23)$ \\
\cline { 2 - 5 } & Present & $22(55)$ & $7(21)$ & $4(11.76)$ \\
\hline \multirow{2}{*}{$\begin{array}{c}\text { Preservation of } \\
\text { nerve }\end{array}$} & Total & $\mathbf{4 0}(\mathbf{1 0 0})$ & $\mathbf{3 4 ( 1 0 0 )}$ & $\mathbf{3 4 ( 1 0 0 )}$ \\
\cline { 2 - 5 } & Absent & $15(37.5)$ & $24(66.6)$ & $26(72.2)$ \\
\cline { 2 - 5 } & Present & $25(62.5)$ & $12(33.3)$ & $10(27.7)$ \\
\hline
\end{tabular}

Incidence of pain after normal daily activities was almost equal in both the study groups at 1 month follow up. Incidence of pain on normal daily activities was $11.76 \%$ in the neurectomy group and $27.7 \%$ in the nervepreservation group after 6 months. The difference in the incidence was found to be significant $(\mathrm{p}=0.001)$.

Table-5: Pain after vigorous activity.

\begin{tabular}{|l|c|c|c|c|}
\hline \multirow{2}{*}{$\begin{array}{l}\text { Pain after vigorous } \\
\text { activities }\end{array}$} & \multicolumn{4}{|c|}{ Follow Up n(\%) } \\
\cline { 2 - 5 } & & $\mathbf{1}$ month & $\mathbf{3}$ months & $\mathbf{6}$ months \\
\hline \multirow{3}{*}{ Neurectomy } & Absent & $21(52.5)$ & $28(82.3)$ & $30(88.2)$ \\
\cline { 2 - 5 } & Present & $19(47.5)$ & $61(7.6)$ & $4(11.7)$ \\
\cline { 2 - 5 } & Total & $\mathbf{4 0}(\mathbf{1 0 0})$ & $\mathbf{3 4 ( 1 0 0 )}$ & $\mathbf{3 4 ( 1 0 0 )}$ \\
\hline \multirow{2}{*}{$\begin{array}{l}\text { Preservation of } \\
\text { nerve }\end{array}$} & Absent & $18(45)$ & $17(47.2)$ & $22(61.2)$ \\
\cline { 2 - 5 } & Present & $22(55)$ & $19(52.7)$ & $14(38.8)$ \\
\cline { 2 - 5 } & Total & $\mathbf{4 0}(\mathbf{1 0 0})$ & $\mathbf{3 6}(\mathbf{1 0 0})$ & $\mathbf{3 6}(\mathbf{1 0 0})$ \\
\hline
\end{tabular}

Incidence of pain after vigorous activity was almost equal in both the study groups at 1 month follow up. But the pain persisted in 14 patients in the nerve preservation group as opposed to 4 patients in the neurectomy group at 6 months follow up $(\mathrm{p}=0.005)$ statistically significant 
Original Research Article

Table-6: Post-operative hypoaesthesia.

\begin{tabular}{|c|c|c|c|c|}
\hline \multirow{2}{*}{$\begin{array}{c}\text { Post-operative } \\
\text { hypoaesthesia }\end{array}$} & \multicolumn{4}{|c|}{ Follow Up n (\%) } \\
\cline { 2 - 5 } & & $\mathbf{1}$ month & $\mathbf{3}$ months & 6 months \\
\hline \multirow{3}{*}{ Neurectomy } & Absent & $28(70)$ & $29(85.2)$ & $30(88.2)$ \\
\cline { 2 - 5 } & Present & $12(30)$ & $5(14.8)$ & $4(11.8)$ \\
\cline { 2 - 5 } & Total & $\mathbf{4 0 ( 1 0 0 )}$ & $\mathbf{3 4 ( 1 0 0 )}$ & $\mathbf{3 4 ( 1 0 0 )}$ \\
\hline Preservation of nerve & Absent & $40(100)$ & $36(100)$ & $36(100)$ \\
\cline { 2 - 5 } & Present & 0 & 0 & 0 \\
\cline { 2 - 5 } & Total & $\mathbf{4 0 ( 1 0 0 )}$ & $\mathbf{3 6 ( 1 0 0 )}$ & $\mathbf{3 6}(\mathbf{1 0 0})$ \\
\hline
\end{tabular}

Incidence of hypoesthesia was $11.8 \%$ in the neurectomy group whereas it was 0 in the nerve preservation group at the 6 months follow up.

Table-7: Post-operative hyperesthesia.

\begin{tabular}{|l|c|c|c|c|}
\hline \multirow{2}{*}{$\begin{array}{l}\text { Post-operative } \\
\text { hyperesthesia }\end{array}$} & \multicolumn{4}{|c|}{ Follow Up n(\%) } \\
\cline { 2 - 5 } & & $\mathbf{1}$ month & $\mathbf{3}$ months & 6 months \\
\hline \multirow{3}{*}{ Neurectomy } & Absent & $28(70)$ & $31(91.1)$ & $34(100)$ \\
\cline { 2 - 5 } & Present & $12(30)$ & $3(8.9)$ & 0 \\
\cline { 2 - 5 } & Total & $\mathbf{4 0}(\mathbf{1 0 0})$ & $\mathbf{3 4 ( 1 0 0 )}$ & $\mathbf{3 4 ( 1 0 0 )}$ \\
\hline \multirow{3}{*}{ Preservation of nerve } & Absent & $26(65)$ & $35(97.2)$ & $35(97.2)$ \\
\cline { 2 - 5 } & Present & $14(35)$ & $1(2.8)$ & $1(2.8)$ \\
\cline { 2 - 5 } & Total & $\mathbf{4 0}(\mathbf{1 0 0})$ & $\mathbf{3 6}(\mathbf{1 0 0})$ & $\mathbf{3 6 ( 1 0 0 )}$ \\
\hline
\end{tabular}

Incidence of hyperesthesia was high in both the study groups a 1 month follow up. At 6 months follow up, only one patient in the nerve preservation group was found to have persistent hyperesthesia at the operated site. In this study, the incidence of post-operative pain is equal among all age groups at end of 6 months.

Table- 8: Type of hernia and post-operative pain.

\begin{tabular}{|c|c|c|c|c|c|c|c|}
\hline \multirow{2}{*}{$\begin{array}{l}\text { Type of } \\
\text { hernia }\end{array}$} & \multirow[t]{2}{*}{ Pain } & \multicolumn{2}{|c|}{1 month } & \multicolumn{2}{|c|}{3 month } & \multicolumn{2}{|c|}{6 month } \\
\hline & & 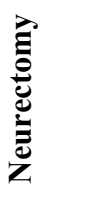 & 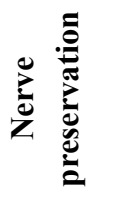 & 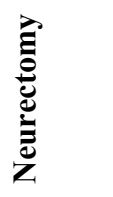 & 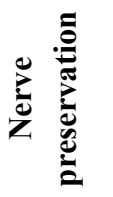 & 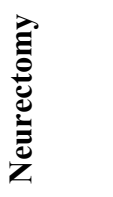 & 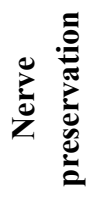 \\
\hline \multirow[t]{2}{*}{ Direct } & Present & 3 & 2 & 2 & 2 & 0 & 1 \\
\hline & Absent & 14 & 9 & 13 & 8 & 15 & 9 \\
\hline \multirow{2}{*}{$\begin{array}{l}\text { Indirect } \\
\text { (incomplete) }\end{array}$} & Present & 7 & 9 & 2 & 6 & 1 & 4 \\
\hline & Absent & 5 & 7 & 8 & 7 & 9 & 9 \\
\hline \multirow{2}{*}{$\begin{array}{l}\text { Indirect } \\
\text { (complete) }\end{array}$} & Present & 9 & 11 & 4 & 10 & 2 & 7 \\
\hline & Absent & 2 & 2 & 5 & 3 & 7 & 6 \\
\hline Total & & 40 & 40 & 34 & 36 & 34 & 36 \\
\hline
\end{tabular}

In this study, the comparison between type of hernia and post-operative pain showed patients with complete inguinal hernia had more incidence of pain than the other type of hernias in both the groups. 


\section{Original Research Article}

\section{Discussion}

The ilioinguinal nerve, although is a content of the inguinal canal, does not enter the canal through the deep inguinal ring. The ilioinguinal nerve arises from the 12th thoracic and first lumbar nerve (T12-L1). It emerges from the lateral border of the Psoas major muscle just below the iliohypogastric nerve and passes obliquely across the Quadratus lumborum and Iliacus then perforates the transverses abdominus, near the anterior part of the iliac crest and communicates with the iliohypogastric nerve, between the Transversus and the Obliquus internus. The nerve then pierces the Obliquus internus (distributing filaments to it) just medial to the anterior superior iliac spine, at this point it becomes visible between the external and internal obliques and then it passes into the inguinal canal, accompanying the spermatic cord, through the subcutaneous inguinal ring. [4-6]

After leaving the superficial inguinal ring, the ilioinguinal nerve subdivides into:

- Large anterior scrotal or labial branches

- Small pubic branch to the lower pubic area and the base of the penis or clitoris

- Crural branches to the upper inner thigh and inguinal crease $[7,8]$.

In Lichtenstein tension-free repair, after reducing the sac, a sheet of polypropylene mesh measuring approximately $8 \times 6 \mathrm{~cm}$ is trimmed to fit the area exposed and used to reconstruct the entire floor of the inguinal canal without any attempt to close the defect by suture [9-13].

The mesh is sutured, along its lower edge, to the pubic tubercle, the lacunar ligament and the inguinal ligament to beyond the internal ring, with polypropylene suture. The superior edge is tacked down to the aponeurosis or muscle of the internal oblique, with a few interrupted sutures. The lateral edge of the mesh is slit and the two tails passed around to embrace the cord at the internal ring, these then are crossed over each other and tacked down to the inguinal ligament with one polypropylene suture. This creates a new internal ring and shutter mechanism [1,14].

Chronic inguinal neuralgia is defined as "pain lasting for 3 months or more," as per the International Association for the study of pain. Post-operative pain has been shown to persist for over 5 years in $1.8 \%$ of patients and as many as $7.5 \%$ of cases may be in more pain than before the operation [15-17].

\section{Diagnosis of neuralgia}

- Neuropathic pain is characterized as an activityinduced sharp pain, located in proximity to the inguinal scar. The pain frequently radiates towards the scrotum, labium and/or upper inner thigh. Upper body stretching or twisting or stooping may cause pain from nerve traction or compression. Application of pressure where the nerve exits the inguinal canal may elicit tenderness in up to $75 \%$ of patients $[18,19]$.

- The neuropathic pain complex can also be reproduced by tapping the skin medial to the anterosuperior spine of the iliac bone or over an area of localized tenderness (Tinel's test). A distinct trigger point situated in or close to the scar may cause pain following stimulation, e.g., after palpation.

- Signs of a disturbed neurophysiological equilibrium including hypoesthesia, hyperesthesia or allodynia in the region of the distribution of the nerve.

- Symptoms usually increase with hip hyperextension (patients walk with the trunk in a forward-flexed posture).

- Local infiltration of anesthetic, with or without steroid, should result in relief within 10 minutes [20].

- Abdominal needle electromyography may be helpful in determining the severity of nerve injury, but electromyography is neither sensitive nor specific. After an appropriate review of available literature and current guidelines and norms, the term neurectomy was applied to the removal of the whole length of the ilioinguinal nerve in the inguinal canal and this procedure was followed in the neurectomy study group. The present study is a comparative study between prophylactic ilioinguinal neurectomy and ilioinguinal nerve preservation in Lichtentein inguinal hernia repair surgeries. The study was conducted with an intention to observe the effect of ilioinguinal neurectomy on the increase or decrease of the incidence of post hernioplasty chronic groin pain and paraesthesia, if any.

One of the early studies in the fields of elective neurectomy in inguinal hernia repair was a pilot study conducted by Ravichandran et al at 2000, in which 20 patients with bilateral inguinal hernia underwent surgery with the ilioinguinal nerve being preserved on one side and divided on the other side, all of the differences in the post surgical pain and numbness between the two sides were insignificant [4]. 


\section{Original Research Article}

Fatemeh malekpour et al 2008, Double blinded randomized controlled clinical trial was performed on 121 patients undergoing open anterior mesh repair of inguinal hernia. Of the 121 patients, 61 were nerve excision group and 60 were nerve preserving group. The chronic post surgical inguinodynia was seen in $6 \%$ in nerve excision group and $21 \%$ in nerve preserved group $(p=0.033)$. Results were concluded that the neurectomy decreases the post surgical pain after elective inguinal hernia repair [5].

Retrospective chart review performed by Dittrick et al 2004, on 90 patients who underwent Lichtenstein inguinal hernia repair. The ilioinguinal nerve was excised in 66 patients and preserved in 24 patients. These investigators concluded that the incidence of neuralgia was significantly lower in the neurectomy group versus the nerve preservation group (3\% vs $26 \%$ $\mathrm{P}<0.001)$. At one year post operatively the neurectomy patient continued to have a significantly lower incidence of neuralgia ( $3 \%$ vs $25 \% \mathrm{p}=0.003$ ).

The incidence of paraesthesia in the distribution of the ilioinguinal nerve was not significantly higher in the neurectomy group ( $13 \%$ vs $5 \%, \mathrm{p}=0.32)$ at 1 year [8]. Patients were followed up in the postoperative period at intervals of 1 month, 3 months and 6 months.

Patients were assessed for post-operative pain and paraesthesia with 10 drop outs occurring within the study period.

Contribution of authors during study process: $\mathrm{Dr}$ Pramoda Sangolagi and Dr Arun kumar Tukaram both are operating surgeons and collected data for analysis.

\section{Conclusion}

In the present study, it was found that chronic groin pain is a significant and debilitating complication following hernia repair. The incidence of pain as well as the severity of pain is far higher in the nerve preservation study group as opposed to the neurectomy study group.

This indicates that prophylactic neurectomy can be an appropriate solution in the prevention of chronic groin pain following Lichtenstein inguinal hernia repair and can be considered as an ideal inclusion into the standard hernia repair procedures.

Hypoesthesia is not a significant complication following ilioinguinal neurectomy and does not significantly add to the morbidity of the patient.
Thus showed the incidence of chronic groin pain is lower in ilioinguinal nurectomy (group A) compared to nerve preservation (group B).

Conflict of interest: None declared.

Funding: Nil, Permission from IRB: Yes

Ethical approval: The study was approved by the institutional ethics committee

\section{References}

1. Nienhuijs SW, van Oort I, Keemers-Gels ME, et al. Randomized trial comparing the Prolene Hernia System, mesh plug repair and Lichtenstein method for open inguinal hernia repair. Br J Surg. 2005 Jan;92(1): 33-8. DOI:10.1002/bjs.4702

2. Geir WP, Kuldeep S, Gillian GK. An algorithm for the treatment of chronic pain after inguinal herniorrhaphy. In : Nyhus LM, Condon RE, editors. Hernia. 5th ed. Philadelphia: JB Lippincott; 2000: 307-16.

3. Bay-Nielsen M, Perkins FM, Kehlet H; et al. Pain and functional impairment 1 year after inguinal herniorrhaphy: a nationwide questionnaire study. Ann Surg. 2001 Jan;233(1):1-7.

4. D. Ravichandran . B. G. Kalambe et al, Pilot Randomized controlled study of Preservation or Division of Ilio-inguinal Nerve in open Mesh Repair of Hernia, Br J Surg $2007 ; 87$ : 1166 -67.9.

5. Malekpour F, Mirhashemi SH, Hajinasrolah E, et al. Ilioinguinal nerve excision in open mesh repair of inguinal hernia--results of a randomized clinical trial: simple solution for a difficult problem? Am J Surg. 2008 Jun;195(6):735-40. doi: 10.1016/j. amjsurg. 2007. 09.037. Epub 2008 Apr 28.

6. Picchio M, Palimento D, Attanasio U, et al. Randomized controlled trial of preservation or elective division of ilioinguinal nerve on open inguinal hernia repair with polypropylene mesh. Arch Surg. 2004 Jul; 139 (7):755-8; discussion 759.

7. Stark E, Oestreich K, Wendl K, et al. Nerve irritation after laparoscopic hernia repair. Surg Endosc. 1999 Sep; 13 (9):878-81.

8. Dittrick GW, Ridl K, Kuhn JA, et al. Routine ilioinguinal nerve excision in inguinal hernia repairs. Am J Surg. 2004 Dec; 188 (6):736-40. DOI:10.1016/j. amjsurg. 2004.08.039 


\section{Original Research Article}

9. Russell RCG, Williams NS, Bulstrode CJK. Hernias, umbilicus and abdominal wall. Bailey and Love's short practice of surgery. 24th ed. London: Arnold; 2004: 1272-93.

10. Robert JF, Charles JF, Thomas HQ. Inguinal Hernias. Schwartz's principles of surgery. 8th ed. Mc Graw Hill; 2005:1353-94.

11. Johnstone JMS, Rintoul RF. Abdominal hernias. Farquharson's textbook of operative surgery. 8th ed. Churchill Livingstone; 2000:523-46.

12. Javid PJ, Books DC, Hernias ZMJ, Ashley SW. Maingot's abdominal operations. 11th ed. New York: McGraw-Hill; 2007:103-39.

13. Fitzgibbons R. Management of an inguinal hernia: Conventional tension free? Laparoscopic? or may be no treatment at all. General session of the American College of Surgeons. 86th Annual Congress; 2000.

14. Celdran A, Frieyro O, Souta JL, Villar S. Study of recurrences after anterior open tension free hernioplasty. In: Nyhus LM, Condon RE, eds. Hernia. 5th ed. Philadelphia: JB Lippincott; 2000:307-16.

15. Ferzli GS, Edwards ED, Khoury GE. Chronic pain after inguinal herniorrhaphy. J Am Coll Surg. 2007 Aug;205(2):333-41. Epub 2007 Jun 27. DOI:10. 1016/j. jamcollsurg.2007.02.081
16. Kalliomäki ML, Meyerson J, Gunnarsson U, et al. Long-term pain after inguinal hernia repair in a population-based cohort; risk factors and interference with daily activities. Eur J Pain. 2008 Feb; 12(2):21425. Epub 2007 Jul 2. DOI: 10.1016/j.ejpain. 2007.05. 006

17. Dennis R, O'Riordan D. Risk factors for chronic pain after inguinal hernia repair. Ann R Coll Surg Engl. 2007 Apr;89(3):218-20. DOI:10.1308/ 003588407 X 178991

18. Vrijland WW, van den Tol MP, Luijendijk RW, et al. Randomized clinical trial of non-mesh versus mesh repair of primary inguinal hernia. Br J Surg. 2002 Mar; 89 (3): 293-7. DOI: 10.1046/j. 0007-1323.2001. 02030.x

19. O'Dwyer PJ, Alani A, McConnachie A. Groin hernia repair: postherniorrhaphy pain. World J Surg. 2005 Aug; 29(8):1062-5. DOI:10.1007/s00268005-7903-0

20. Alfieri S, Rotondi F, Di Miceli D, Di Giorgio A, PericoliRidolfini M, Fumagalli U, et al. Chronic pain after inguinal hernia mesh repair: possible role of surgical manipulation of the inguinal nerves: A perspective multicentre study of 973 cases. Chir Ital.2006;58:23-31.

\section{How to cite this article?}

Sangolagi P, Tukaram A.K. Comparative study of prophylactic ilioinguinal neurectomy and preservation of ilioinguinal nerve in open mesh repair of inguinal hernia. Surgical Update: Int J surg Orthopedics.2018;4(4):157-164.doi:10.17511/ ijoso.2018.i04.05. 